\title{
EKSPLORASI ETNOMATEMATIKA PADA KEBUDAYAAN SUKU DAYAK SEBAGAI SUMBER BELAJAR MATEMATIKA DI SMP NEGERI 1 LINGGANG BIGUNG KUTAI BARAT
}

\author{
Ariantje Dimpudus ${ }^{1)}$ \\ Angela Carolina Huring Ding \\ ${ }^{1)}$ Dosen Pendidikan Matematika FKIP Universitas Mulawarman \\ Email: ${ }^{1)}$ ariantjemath@gmail.com
}

\begin{abstract}
ABSTRAK
Pengabdian pada masyarakat ini bertujuan untuk memberikan pelatihan kepada guruguru SMP Negeri 1 Linggang Bigung Kutai Barat tentang etnomatematika berbasis suku Dayak dan untuk memberikan pengalaman kepada guru tentang pembelajaran matematika berbasis suku Dayak serta untuk mendapatkan gambaran bagaimana tanggapan guru-guru tentang etnomatematika. Pengabdian ini dilaksanakan melalui tahapan usulan sampai pelaporan yakni dari bulan Mei sampai dengan Oktober 2018. Lokasi kegiatan di SMP Negeri 1 Lingang Bigung Kutai barat yang terletak di Jalan Pelajar, Rt. VII Linggang Bigung. Metode pengabdian ini menggunakan metode ceramah, diskusi, dan pemodelan. Ceramah digunakan untuk memberikan penjelasan dan informasi tentang etnomatematika dilanjutkan dengan diskusi untuk mengidentifikasi budaya suku Dayak yang memuat konsep matematika. Kemudian dilanjutkan dengan pemodelan pembelajaran berbasis etnomatematika. Dengan kegiatan pengabdian ini diharapkan motivasi dan kemandirian belajar matematika meningkat dan kualitas pembelajaran semakian baik serta berdampak pada peningkatan hasil belajar matematika siswa.
\end{abstract}

Kata kunci: Etnomatematika, Pembelajaran Matematika

\begin{abstract}
This community services aims provide training to teachers of SMPN 1 Linggang Bigung Kutai Barat on ethnomathematics based on Dayak tribe dan provide teachers with experience on learning of Dayak tribe-based mathematics and get an overview of how teacher respond to ethnomathematics. This service is carried out through the stages of the proposal until reporting, namely from May to October 2018. The location of the activity at SMPN 1 Linggang Bigung Kutai Barat, located on Jalan Pelajar Rt. VII Linggang Bigung. This service metod use lecture, discussion, and modeling method. The lecture is used to give explanations and information about ethnomathematics folowed by a discussion to identify the culture of the Dayak tribe which contain mathematical concept. The, proceed with ethnomatematics based learning modeling. With this dedication activity, it is expected that the motivation and independence of learning mathematics will increase and the quality of learning improve and have an impact on improving student mathematics learning outcomes.
\end{abstract}

Keywords: Ethnomatematics, Learning Mathematics 


\section{PENDAHULUAN}

Upaya meningkatkan kualitas pendidikan dan pembelajaran matematika terus dilaksanakan. Ada kegiatan pelatihan/workshop materi ajar matematika, perangkat pembelajaran, media pembelajaran, dan kegiatan-kegiatan lainnya yang dilaksanakan dengan satu tujuan yakni meningkatkan kualitas pembelajaran. Hal ini jelas terkait dengan masalah pembelajaran dan hasil belajar mata pelajaran matematika yang cenderung lebih rendah dibandingkan pelajaran-pelajaran lainnya. Banyak faktor yang menyebabkan rendahnya prestasi belajar siswa. Salah satunya adalah proses pembelajaran masih terpusat pada guru (teacher centered learning) dengan kata lain guru merupakan sosok pembawa pesan. Berbagai faktor yang ada seharusnya guru matematika harus bekerja lebih dari sebelumnya untuk menggabungkan upaya reformasi untuk menyediakan pendidikan matematika bermakna bagi semua siswa yang berhubungan dengan isu-isu dunia nyata.

Berbagai media dimanfaatkan untuk membantu pemahaman konsep matematika siswa, namun tidak jarang media yang digunakan hanyalah model dari bangun susungguhnya, sehingga wujud sesungguhnya dari model yang terkadang sangat berbeda tampilan dengan benda sesungguhnya membingungkan siswa. Pelajaran matematika seolah-olah jauh dari kehidupan sehari-hari. Meskipun disadari atau tidak sesungguhnya banyak fakta dan konsep matematika sudah diterapkan orqang dalam kehidupannya sehari-hari, namun demikian tidak semua orang yakin dengan kegunaan/manfaat matematika sehingga mengalami kesulitan belajar an memahami matematika, bahkan pesimis dan apatis belajar matematika.

Salah satu kompetensi inti pelajaran matematika adalah memahami pengetahuan (factual, konseptual, dan prosedural) berdasarkan rasa ingin tahu tentang ilmu pengetahuan, teknologi, seni, budaya terkait fenomena dan kejadian tampak mata. Mencermati kompetensi pelajaran matematika yang harus dikuasai siswa, maka terlihat bahwa siswa dituntut tidak saja menguasai pengetahuan tapi juga budaya yang terkait dengan fenomena yang tampak nyata. Pelajaran matematika selalu diajarkan di sekolah sebagai satu mata pelajaran yang tidak bergantung pada budaya tertentu. Namun demikian tidak sedikit konsep matematika diaplikasikan pada budaya tertentu.

Dalam berbagai kegiatan yang kami lakukan dengan masyarakat terutama guruguru dan siswa di Kabupaten Kutai Barat, baik sebagai instruktur dalam kegiatan diklat pendidikan/pembelajaran, sebagai tutor pada kegiatan tutorial guru-guru yang melanjutkan studi di Universitas Terbuka dan lain-lain. Kami menemukan banyak siswa bahkan guru yang kurang termotivasi untuk belajar matematika, meskipun dalam proses pembelajaran sudah menggunakan media baik dalam bentuk alat peraga maupun media power point. Anggapan bahwa untuk belajar matematika hanyalah mungkin dikuasai orang-orang pintar, sehingga merasa bahwa walaupun mereka mempelajarinya tetap saja tidak bisa menguasainya. Begitu pula kondisinya mahasiswa program studi pendidikan matematika yang berasal dari Kabupaten Kutai Barat pada umumnya indeks prestasi komulatif (IP) tergolong rendah. Dalam

112 Eksplorasi etnomatematika pada kebudayaan suku Dayak sebagai sumber belajar matematika Ariantje Dimpudus - Angela Carolina Huring Duing 
kondisi seperti ini perlu dipertimbangkan suatu model pembelajaran yang dapat mendekatkan matematika dengan budaya tertentu untuk membangun rasa percaya diri dan motivasi belajar matematika.

Etnomatematika mengacu pada konsep-konsep matematika yang tertanam dalam praktek-praktek budaya dan mengakui bahwa semua budaya dan semua orang mengembangkan metode unik untuk memahami dan mengubah realitas komunitas budaya. Selanjutnya dikatakan bahwa etnomatematika merupakan sebuah studi tentang perbedaan cara masyarakat memecahkan masalah matematika dan algoritma praktis berdasarkan perspektif matematika masyarakat sendiri. Etnomatematika mengacu pada bentuk-bentuk matematika yang bervariasi sebagai konsekuensi yang tertanam dalam kegiatan budaya.

Tujuan dari kajian tentang etnomatematika:

a. Agar keterkaitan antar matematika dan budaya bias lebih dipahami, sehingga persepsi siswa dan masyarakat tentang matematika menjadi lebih tepat dan pembelajran matematika dapat lebih disesuaikan dengan konteks budaya siswa dan masyarakat, dan matematika dapat lebih mudah dipahami karena tidak lagi dipersepsikan sebagai sesuatu yang "asing" oleh siswa dan masyarakat.

b. Agar aplikasi dan manfaat matematika bagi kehidupan siswa dan masyarakat luas lebih dapat dioptimalkan sehingga siswa dan masyarakat memperoleh manfaat optimal dari kegiatan belajar matematika.

Melalui pembelajaran berbasis etnomatematika suku Dayak di SMPN 1
Linggang Bigung, dengan mayoritas masyarakat dan siswa bersuku Dayak di Kabupatren Kutai Barat kiranya dapat membangkitkan motivasi belajar dan kemandirian belajar siswa dan guru dalam proses pembelajaran serta dapat meningkatkan hasil belajar matematika siswa. Disisi lainnya melalui pembelajaran etnomatematika dapat meningkatkan kecintaan masyarakat terhadap budayanya dan cinta tanah air.

\section{METODE PENELITIAN}

Kegiatan pengabdian ini dilaksanakan selama 6 bulan sejak dimulai usulan kegiatan pada bulan April 2018, penyusunan program dan persiapan media sampai pelaksanaan kegiatan. Sebelum kegiatan ini dilaksanakan naka terlebih dahulu kami menghubungi kepala sekolah SMPN 1 Linggang Bigung dan menjelaskan maksud serta tujuan pelaksanaan kegiatan pengabdian ini. Metode yang digunakan dalam kegaitan pengabdian ini adalah

a. Ceramah, digunakan untuk memberikan penjelasan/informasi tentang etnomatematika kepada guru-guru dan kepala sekolah SMPN 1 Linggang Bigung.

b. Diskusi, digunakan untuk mengidentifikasi budaya, ornamen, dan asesoris suku Dayak yang memuat konsep matematika. Diskusi dilakukan bersaOma dengan kepala sekolah, guru, dan tenaga administrasi yang bertugas di SMPN 1 Linggang Bigung.

c. Parkatek, digunakan untuk berlatih menyusun perangkat pembelajaran berbasis etnomatematika dan pemodelan untuk kegiatan pembelajaran. Kegiatan ini dilakukan setelah teridentifikasi 
unsur-unsur yang mengandung konsep matematika, menyusun perangkat pembelajaran untuk satu kompetensi dasar dan memilih satu atau dua guru mempraktekkan rencana pembelajaran yang telah disusun.

\section{HASIL KEGIATAN DAN PEMBA- HASAN}

\section{A. Hasil Kegiatan Pengabdian}

Kegiatan pengabdian ini dilaksanakan dengan tujuan (a) memberikan pelatihan kepada guru SMPN 1 Linggang Bigung Kutai Barat tentang etnomatematika berbasis budaya suku Dayak, (b) memberikan pengalaman kepada guru tentang pembelajaran etnomatematika berbasis suku dayak melalui model, (c) mengetahui tanggapan guru tentang pembelajaran etnomatematika. Kegiatan ini dilaksanakan pada tanggal 9-12 Agustus 2018 di SMPN 1 Linggang Bigung, Kabupaten Kutai Barat Kalimantan Timur. Kegiatan pengabdian masyarakat ini diikuti oleh guru-guru, kepala sekolah, kepala tata usaha, dan tenaga administrasi SMPN 1 Linggang Bigung. Kegiatan ini didahului dengan sambutan kepala sekolah, kemudian dilanjutkan dengan pemberian informasi dari team tentang etnomatematika dan pemodelan dimana dua orang guru secara bergantian mencoba mengajarkan materi matematika berbasis etnomatematika suku Dayak.

Berikut ini hasil identifikasi budaya suku Dayak yang memuat konsep matematika.

1. Baju adat perempuan (basung dohbahau)
Pada baju adat wanita ini dinamakan basung doh (bahau) mengandung unsur matematika yakni segitiga dan simetri lipat.

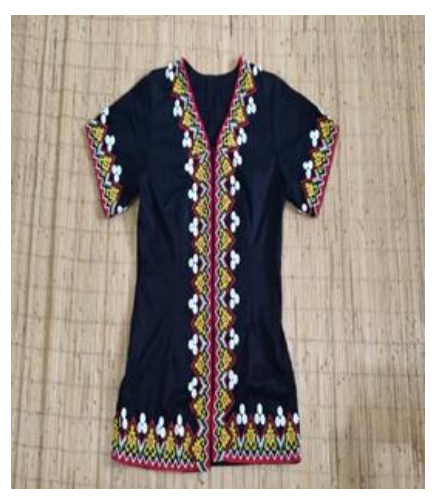

Gambar 1. Basung doh-bahau

2. Topi adat lavung

Topi adat pada gambar 2 dinamakan lavung, yang mengandung unsur matematika yakni tabung tanpa alas dan tutup.

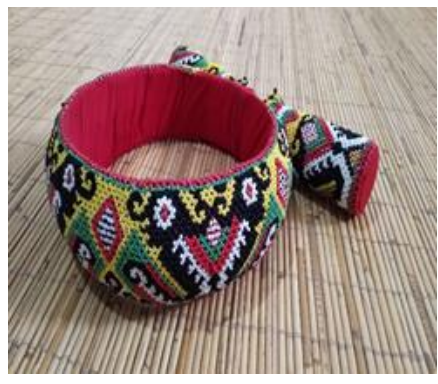

Gambar 2. Lavung

\section{Rok adat (Taah-Bahau)}

Rok adat wanita pada gambar 3 dinamakan Taah (Bahau) mengandung unsur matematika yakni trapesium dan persegi panjang.

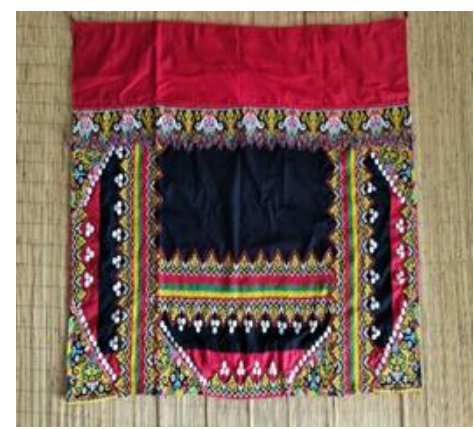

Gambar 3. Taah-bahau 


\section{Upacara adat belian}

Pada upacara adat belian (Dayak Tunjung) para pria menggunakan kostum dengan berbagai corak geometris seperti belah ketupat, laying-layang, segitiga dan sebagainya.

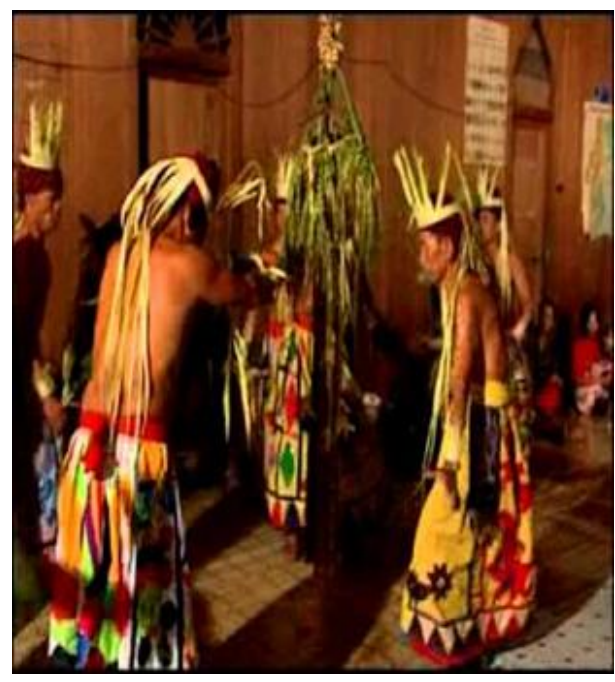

Gambar 4. Upacara adat belian

5. Anjat

Anjat semacam ransel atau tas yang dibuat oleh ibu rumah tangga dan banyak digunakan untuk berbagai keperluan. Pada anjat terdapat konsep matematika seperti tabung, persegi, layang-layang, belah ketupat, dan lain-lain.

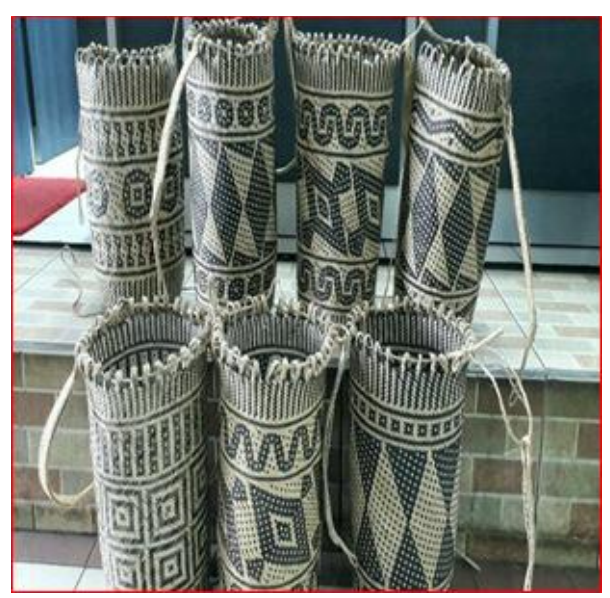

Gambar 5. Anjat
6. Seraung, tameng, dan selendang

Pada sarung, tameng, dan selendang terdapat konsep matematika seperti kerucut dan persegi panjang.

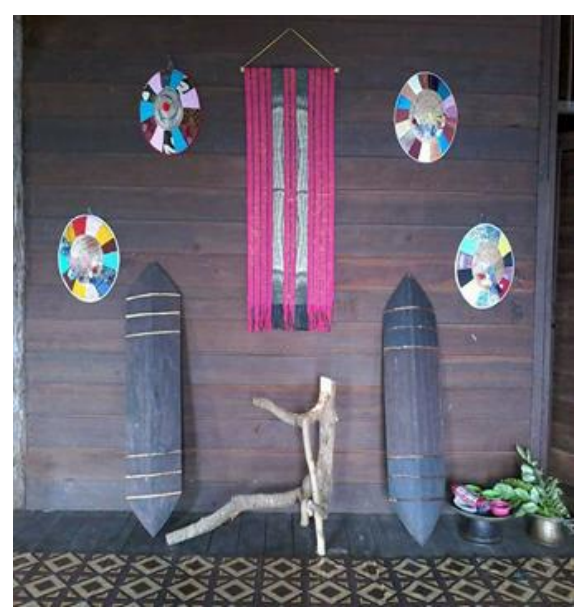

Gambar 6. Seraung, tameng, dan selendang

Setelah kegiatan pelatihan selesai dilaksanakan maka team mendapat informasi mengenai tanggapan guru/peserta tentang pembelajaran etnomatematika. Untuk keperluan ini dibagikan daftar pertanyaan sebagai berikut:

1. Bagaimana tanggapan bapak/ibu tentang etnomatematika?

2. Apakah perlu pembelajaran berbasis etnomatematika?

3. Apa saran bapak/ibu untuk perkembangan etnomatematika selanjutnya?

Berikut ini rangkuman tanggapan peserta tentang etnomatematika berbasis budaya suku Daya. Jawaban pertanyaan nomor satu sebagai berikut: $37,5 \%$ peserta menjawab etnomatematika penting dalam kehidupan berbudaya masyarakat. 31,25\% menganggap etnomatematika merupakan ilmu yang berakaitan dengan kehidupan sehari-hari. $12,5 \%$ merasa etnomatematika merupakan ilmu yang menambah wawasan 
dan pemahaman. 12,5\% menganggap etnomatematika dapat memudahkan pemahaman materi pelajaran matematika dan $6,25 \%$ menganggap etnomatematika membahas mengenai budaya atau kebia-saan sehari-hari.

Untuk pertanyaan nomor dua hanya terdapat dua kelompok jawaban yaitu $25 \%$ emngganggap perlu dan $75 \%$ merasa sangat perlu. Jawaban pertanyaan nomor tiga ada empat kategori yakni 50\% menjawab harus banyak referensi tentang kebudayaan-kebudayaan, 12,5\% menganggap perlu disosialisasikan lagi ke daerahdaerah dan pihak-pihak terkait, 12,5\% merasa perlu ada pelatihan dan pembinaan khusus, dan $25 \%$ merasa perlu ditingkatkan dan diterapkan di sekolah-sekolah.

\section{B. Pembahasan}

Memahami pengetahuan (faktual, konseptual, dan prosedural) berdasarkan rasa ingin tahu tentang ilmu pengetahuan, teknologi, seni, dan budaya terkait fenomena dan kejadian tampak mata merupakan salah satu kompetensi inti pelajaran matematika SMP. Untuk memiliki kompetensi ini guru perlu merancang proses pembelajaran yang tidak saja diarahkan pada penguasaan pengetahuan secara konseptual tetapi juga faktual dan prosedural. Pembelajaran tidak saja kontekstual tetapi juga menyentuh unsurunsur budaya. Matematika memang tidak bergantung pada budaya tertentu, tetapi banyak unsur-unsur budaya menggunakan konsep-konsep matematika.

Tujuan dari kajian tentang etnomatematika:

1. Agar ketertarikan antara matematika dan budaya dapat lebih dipahami sehingga persepsi siswa dan masya- rakat tentang matematika menjadi lebih tepat dan lebih disesuaikan dengan konteks budaya.

2. Agar aplikasi dan manfaat matematika bagi kehidupan siswa dan masyarakat luas lebih dioptimalkan.

Suku Dayak merupakan salah satu suku tertua di pulau Kalimantan, lebih khusus di Kabupaten Kutai Barat Kecamatan Linggang Bigung. Aktivitas dan kehidupan masyarakat sehari-hari tidak lepas dari kebudayaan yang mereka miliki. Berikut ini akan dijelaskan pakaian adat dan beberapa benda yang dibicarakan pada kegiatan eksplorasi etnomatematika:

1. Ta'ah, merupakan sebuah pakaian dari tenunan kain persegi empat yang dipergunakan wanita dengan cara melilitkan pada seputar panggul pinggang ke bagian bawah sampai dipergelangan kaki.

2. Lavung, merupakan jenis pakaian dalam masyarakat bahau yang digunakan untuk menutupi rambut dan berbentuk tabung.

3. Kelebee, merupakan jenis untaian rangkaian manik-manik yang dianyam lebar dengan ukuran kira-kira $15 \mathrm{~cm} \times$ $45 \mathrm{~cm}$. Anyaman manik-manik pada kelebee berbentuk kongruen dan simetri.

4. Bahalai, merupakan sejenis kain tenun halus yang berukuran Panjang tetapi kecil yang berupa jenis selendang yang digunakan melingkar dileher.

5. Inuuq, merupakan untaian atau rangkaian manik-manik dalam beberapa ukuran.

6. Basung, merupakan baju wanita yang berbentuk belah tengah tanpa kerah dan tanpa lengan. 
Aspek dekoratif pakaian tradisi adat Bahau sangat kaya dengan warna dan bentuk-bentuk geometris. Dalam kegiatan pengabdian yang dilaksanakan, eksplorasi dilakukan tidak untuk mendalami makna upacara atau kegiatan kebudayaan yang dilakukan masyarakat disana, tetapi yang di pelajari adalah konsep matematika apa yang terkandung dalam upacara atau kegiatan bahkan produk-produk yang dihasilkan masyarakat.

Respon positif terlihat dari peserta pelatihan dimana sebagian besar menganggap kajian tentang etnomatematika penting dalam kehidupan kebudayaan masyarakat dan berkaitan dengan kehidupan seharihari, menambah wawasan dan pemahaman serta memudahkan pemahaman materi pelajaran matematika. Terlihat pula semangat peserta untuk mengingat dan menyebutkan apa saja benda-benda yang biasa mereka gunakan sehari-hari dan mengandung konsep matematika. Meskipun pada saat kegiatan ini berlangsung, peserta kegiatan tidak semua merupakan guru pelajaran matematika, namun terlihat antusias peserta dalam bertanya dan mengemukakan pendapatnya.

Hampir semua peserta merasa etnomatematika sangat perlu diterapkan disekolah-sekolah dengan dilengkapi referensi tentang kebudayaan-kebudayaan serta disosialisasikan lagi kedaerah-daerah dan sekolah-sekolah yang lain. Keinginan untuk mengembangkan etnomatematika meskipun baru mendapatkan sedikit informasi tentang etnomatematika, hal ini nampak dikarenakan etnomatematika terkait dengan budaya. Kecintaan terhadap budaya membuat seseorang tertarik mendiskusikannya.

\section{KESIMPULAN}

Berdasarkan hasil penelitian dapat disimpulkan bahwa:

1. Dalam kegiatan eksplorasi etnomatematika telah teridentifikasi beberapa tradisi dan pakaian adat suku Dayak di Kabupaten Kutai barat yang memuat konsep matematika, seperti baju adat perempuan (Basuung Doh-Bahau), topi adat (Lavung), rok adat (Taah-Bahau), anjat, seraung, tameng, dan selendang.

2. Tanggapan peserta sangat positif dengan menganggap etnomatematika sangat perlu dilakukan sosialisasi lagi dan diterapkan disekolah-sekolah. $37,5 \%$ peserta menjawab etnomatematika penting dalam kehidupan kebudayaan masyarakat. 31,25\% menganggap etnomatematika merupakan ilmu yang berkaitan dengan kehidupan sehari-hari. $12,5 \%$ merasa etnomatematika merupakan ilmu yang menambah wawasan dan pemahaman. $12,5 \%$ menganggap etnomatematika dapat memudahkan pemahaman materi pelajaran matematika dan 6,25\% menganggap etnomatematika membahas mengenai budaya atau kebiasaan sehari-hari. $25 \%$ menganggap perlu dan $75 \%$ merasa sangat perlu. 50\% menjawab harus banyak referensi tentang kebudayaan-kebudayaan, 12,5\% menganggap perlu disosialisasi-kan lagi kedaerah-daerah dan pihak-pihak terkait, $12,5 \%$ merasa perlu ada pelatihan dan pembinaan khusus, dan $25 \%$ merasa perlu ditingkatkan, dikembangkan dan diterapkan disekolahsekolah. 


\section{DAFTAR PUSTAKA}

Budiarto, Mega Teguh. (2016). Etnomatematika Beberapa Budaya Nusantara: Sebagai Batu Pijakan Pembelajaran Geometri. Makalah disajikan dalam Konferensi Nasional Matematika XVIII 2-5 November 2016.

Fujiati dan Mastur. (2014). Keefektifan Model Pogil Berbantuan Alat Peraga Berbasis Etnomatematika Terhadap Kemampuan Komunikasi Matematis. Unnes: Journal of Mathematics Education.

Ismawanto. (2014). Pengembangan CD Interaktif Berbantuan Swishmax dengan Model Etnomatematika pada Materi Bangun Ruang Sisi Datar Kelas VIII Semester II. Prosiding Mathematics and Sciences Forum 2014. Vol 2. No. 2. Hal 527-534. ISBN 978-602-0960$00-5$.

Khoirin, Izza. (2017). Pengembangan Comic Math dengan Pendekatan EtnoMatematika Pada Meteri Kubus Dan Balok Di SMP. FPMIPATI, Universitas PGRI Semarang Jurnal Aksioma Vol 8 No.1 Juli 2017.
Prabawati, Mega Nur. (2016). Etnomatematika Masyarakat Pengrajin Anyaman Rajapolah Kabupaten Tasikmalaya. Infinity Jurnal Ilmiah Program Studi Matematika STKIP Siliwangi Bandung, Vol 5, No. 1, Februari 2016.

Reilly, Edel M. (2014). Superheroes in Math Class: Using Comics to Teach Diversity Awareness. International Journal work and days Vol. 32. No. $1 \& 2$. Hal 61-74

Sardjiyo dan Pannen. Pembelajaran Berbasis Budaya: Model Inovasi Pembelajaran dan Implementasi Kurikulum Berbasis Kompetensi, Jurnal Pendidikan. 6(2), 2005.

Suwarsono.St. 2015. Etnomatematika (Ethnomathematics). Bahan Presen-tasi. Program S2 Pendidikan Matematika Universitas Sanata Dharma Yogyakarta.

Theresia Laurens. 2016. Analisis Etnomatematika dan Penerapannya Dalam Meningkatkan Kualitas Pembelajaran. Lemma Jurnal Ilmiah Vol III No. 1, Juni 2016. STKIP PGRI Sumatra Barat. 